\title{
Population studies of sporadic cerebral amyloid angiopathy and dementia: a systematic review
}

\author{
Hannah AD Keage*1, Roxanna O Carare2 ${ }^{2}$, Robert P Friedland 3 , Paul G Ince ${ }^{4}$, \\ Seth Love ${ }^{5}$, James A Nicoll2 ${ }^{2}$ Stephen B Wharton ${ }^{4}$, Roy O Weller ${ }^{2}$ and \\ Carol Brayne ${ }^{1}$
}

Address: ${ }^{1}$ Department of Public Health and Primary Care, University of Cambridge, Cambridge, CB2 0SR, UK, ${ }^{2}$ Division of Clinical Neurosciences, School of Medicine, University of Southampton, Southampton, SO16 6YD, UK, ${ }^{3}$ School of Medicine, Case Western Reserve University, Cleveland, Ohio, 44106, USA, ${ }^{4}$ Academic Unit of Pathology, University of Sheffield, Sheffield, S10 2RX, UK and ${ }^{5}$ Bristol Neuroscience, University of Bristol, Bristol, BS8 1TD, UK

Email: Hannah AD Keage* - hk323@medschl.cam.ac.uk; Roxanna O Carare - R.O.Carare@soton.ac.uk; Robert P Friedland - robert.friedland@case.edu; Paul G Ince - P.G.Ince@sheffield.ac.uk; Seth Love - seth.love@bristol.ac.uk; James A Nicoll - J.Nicoll@soton.ac.uk; Stephen B Wharton - s.wharton@sheffield.ac.uk; Roy O Weller - row@soton.ac.uk;

Carol Brayne-cb105@medschl.cam.ac.uk

* Corresponding author

Published: 13 January 2009

BMC Neurology 2009, 9:3 doi:10.1 186/147/-2377-9-3
Received: 17 September 2008

Accepted: 13 January 2009

This article is available from: http://www.biomedcentral.com/I47/-2377/9/3

(C) 2009 Keage et al; licensee BioMed Central Ltd.

This is an Open Access article distributed under the terms of the Creative Commons Attribution License (http://creativecommons.org/licenses/by/2.0), which permits unrestricted use, distribution, and reproduction in any medium, provided the original work is properly cited.

\begin{abstract}
Background: Deposition of amyloid- $\beta(A \beta)$ in vessel walls of the brain as cerebral amyloid angiopathy (CAA) could be a major factor in the pathogenesis of dementia. Here we investigate the relationship between dementia and the prevalence of CAA in older populations. We searched the literature for prospective population-based epidemiological clinicopathological studies, free of the biases of other sampling techniques, which were used as a comparison.
\end{abstract}

Methods: To identify population-based studies assessing CAA and dementia, a previous systematic review of population-based clinicopathological studies of ageing and dementia was employed. To identify selected-sample studies, Psychlnfo (I806-April Week 3 2008), OVID MEDLINE (1950April Week 2 2008) and Pubmed (searched 2 I April 2008) databases were searched using the term "amyloid angiopathy". These databases were also employed to search for any population-based studies not included in the previous systematic review. Studies were included if they reported the prevalence of CAA relative to a dementia classification (clinical or neuropathological).

Results: Four population-based studies were identified. They showed that on average $55-59 \%$ of those with dementia displayed CAA (of any severity) compared to $28-38 \%$ of the non-demented. $37-43 \%$ of the demented displayed severe CAA in contrast to $7-24 \%$ of the non-demented. There was no overlap in the range of these averages and they were less variable and lower than those reported in 38 selected sample studies (demented $v$ non-demented: $32-100 \vee 0-77 \%$ regardless of severity; 0-50 ₹ 0-1 I\% for severe only).

Conclusion: CAA prevalence in populations is consistently higher in the demented as compared to the non-demented. This supports a significant role for CAA in the pathogenesis of dementia. 


\section{Background}

Alzheimer's disease (AD) is the most common type of dementia and is characterised pathologically by the intraneuronal accumulation of neurofibrillary tangles (NFT) containing tau and ubiquitin, and by the extracellular accumulation of amyloid- $\beta(A \beta)$ in brain tissue and in artery walls as cerebral amyloid angiopathy (CAA). Many studies have correlated the severity of dementia in AD with the number and distribution of NFTs, the number of plaques of insoluble $A \beta$, and the levels of soluble $A \beta$ in the brain [as reviewed by [1]]. Relatively few studies, however, have investigated the relationship between dementia and the key pathological change of CAA.

$\mathrm{CAA}$ is the deposition of the amyloid peptides, of which $\mathrm{A} \beta$ is the most common, in the media and adventitia of small to medium-sized cerebral and leptomeningeal arteries, and less commonly in the walls of capillaries and veins [2-5]. The occipital lobe is most often involved, the frontal, parietal and temporal lobes less so and the cerebellum least; CAA is rare in the thalamus, basal ganglia and white matter [6,7]. Scholz [8] first emphasized the presence of CAA, suggesting that the pathological feature was associated with 'senility'. However, CAA was only reported to be a risk factor for dementia in the 1980s [911]. There has since then been increasing evidence to support this proposal $[12,13]$ and CAA is now thought to play a significant role in the production of dementia [14-16]. Hereditary and sporadic types of CAA have been defined $[17,18]$ however this review focuses on the common sporadic CAA found in the old.

The cause and effects of CAA have generated much debate especially in relation to dementia $[19,20]$. CAA represents the failure of elimination of $\mathrm{A} \beta$ along the perivascular pathways that serve as the lymphatic drainage channels for the brain [20]. Soluble tracers injected into the mouse striatum drain out of the brain along basement membranes of capillary and artery walls [21]. In CAA, A $\beta$ is deposited in the very same perivascular drainage pathways outlined, in capillary and artery walls, in the injection studies in mice. This suggests that there is a failure of elimination of $\mathrm{A} \beta$ along ageing cerebral and leptomeningeal arteries [20,22,23]. Stiffening of artery walls with age and cerebrovascular disease may be a key element in reducing the elimination of $A \beta$ from the brain in the elderly and in AD $[20,24,25]$. Transgenic mice that overproduce A $\beta$ only in the brain develop CAA [19] which further supports the hypothesis that, in CAA, $A \beta$ is entrapped in the perivascular pathways by which fluid and solutes drain from the brain $[20,22]$.

Two major consequences arise from CAA. First: arteries weakened by deposits of $A \beta$ in their walls tend to rupture and result in CAA-related intracerebral haemorrhage
$[26,27]$. Second: blockage of perivascular drainage pathways by $A \beta$ may be associated with accumulation of $A \beta$ in the brain. Ultimately it is increased levels of soluble $A \beta$ that correlates with cognitive decline in patients with $\mathrm{AD}$ $[28,29]$. It is possible that drainage of other soluble metabolites from the brain may also be impeded in CAA. This would result in a loss of homeostasis in the neuronal extracellular environment that could contribute to cognitive decline in $\mathrm{AD}$ [20].

CAA has been related to other neuropathological markers of dementia including neuritic plaques and NFTs [30-32]. The amount of phospho-tau in neurites was found to be greater in grey matter surrounding cerebral vessels affected by CAA than in grey matter away from affected vessels [33]. The relationship between CAA and other neuropathologies is not simple however, and there is great heterogeneity in CAA severity in brains with AD-type pathology [34]. CAA has been reported to affect cognition/dementia status independently of other neuropathological markers of dementia $[3,7,12,35,36]$. However, in one study CAA was found to be associated with dementia only in those who lacked any AD-type pathology [37].

Assessing the possible impact of CAA or any neuropathological marker of dementia is best done using a sample that closely reflects the population at risk [38]. The vast majority of studies assessing the relationship between CAA and dementia have assessed selected samples (e.g., necropsy and hospital patients) which do not reflect the population at risk, in terms of either clinical or age profiles. Many of these studies have had access to limited clinical information, which further limits the interpretation of results. Thus, although CAA has been reported to play a significant role in the causation of dementia, it is unknown whether this is partly an artefact of using highly selected samples and/or the predominant use of neuropathological dementia classifications such as $\mathrm{AD}$ (which most likely relates to CAA closer than clinical diagnoses). The role of CAA in dementia at a population level is uncertain.

Our aim in this study was to investigate the importance of CAA in relation to dementia in a population-based context. We have addressed this by systematically reviewing previous studies that have assessed the relationship between CAA and dementia in prospectively sampled population-based cohorts of elderly people. For comparison, we have systematically reviewed studies of CAA on selected samples.

\section{Methods Identifying population-based studies for review}

A systematic review of population-based neuropathological studies of ageing and dementia in older people was published in 2006 [39]. Six studies were identified as 
being fully population-based - the Hisayama Study (Japan), Vantaa 85+ (Finland), the Cambridge City over 75 Cohort (CC75C; England), the Honolulu-Asia Aging Study (HAAS; USA), the Cache Country Study (USA) and the MRC Cognitive Function and Ageing Study (CFAS; England and Wales). To identify articles for the current review, PsychInfo (1806-April Week 3 2008), OVID MEDLINE (1950-April Week 2 2008) and Pubmed (searched 21 April 2008) databases were used to search for papers employing any of these six study populations to assess CAA. Study titles were searched for as keywords, along with 'amyloid angiopathy'. When no study could be found using the key term 'amyloid angiopathy', it was replaced by 'neuropathology' and the relevant articles were read and searched to determine if CAA was assessed. To ensure that no further prospective population-based clinicopathological studies had been published since Zaccai et al. [39], a search was conducted using the same databases detailed above using the terms 'population' and 'amyloid angiopathy' or 'pathology'. No new studies were identified.

\section{Identifying selected-sample studies for review}

To compare CAA prevalence rates in population-based studies with those in studies of selected samples, we conducted a systematic review of studies in which CAA prevalence was determined relative to dementia status.

To identify studies using selected samples the PsychInfo (1806-April Week 3 2008), OVID MEDLINE (1950-April Week 2 2008) and Pubmed (searched 21 April 2008) databases were searched. One thousand three-hundred and seventy-three studies were identified using the search term 'amyloid angiopathy'. Titles and abstracts from these studies were read and studies were excluded if they did not assess human cases, the prevalence of CAA in the demented and/or non-demented specifically related to hereditary/familial CAA, reported a sample with a $n$ less than 10, reported CAA prevalence relative to a condition other than dementia or only a feature of dementia (e.g., Parkinson's disease or APOE genotype), selected cases based on the presence of CAA, if they clearly reported the same cases as a previously selected study [e.g., [30,40,41]], if analyses were not neuropathological (e.g., MRI), or had been included as one of the population-based studies described above. The search was restricted to the English language. When a decision could not be made as to whether the article should be excluded, full articles were read. When articles were read, any cited articles that were not identified during the search were included.

\section{Results}

\section{Summary of findings from population-based studies}

Five of the six population-based studies reported CAA prevalence rates $[13,14,35,42,43]$, of which four calcu- lated these rates relative to dementia status (demented and/or non-demented) prior to death [all but [43]]. The findings from the four studies identified are reviewed below and summarised in Additional file 1. None of the studies assessed sex differences and only one study provided prevalence relative to age-groups [14] and thus prevalence relative to age and sex factors are not shown.

\section{Cambridge City over 75 Cohort (CC75C)}

Xuereb et al. [42] reported on CAA prevalence in the CC75C. The study comprised 99 individuals $(68 \%$ women) over 80 years of age. CAA was assessed in meningeal and parenchymal areas of the occipital, frontal, temporal and parietal cortices as well as in the hippocampus. All CAA was recorded, regardless of severity. The authors reported that regardless of distribution, brains from participants with clinical dementia had a significantly higher prevalence of CAA (55\%) than brains from participants who were not demented (26\%).

\section{MRC Cognitive Function and Ageing Study (MRC-CFAS)}

MRC-CFAS [14] assessed the association between severe CAA and clinical dementia in 209 (57\% female) individuals from England with a mean age of 86 years. Parenchymal and meningeal CAA was scored in the entorhinal, frontal, temporal, parietal and occipital cortices as well as the hippocampus. Severe CAA was present in $37 \%$ of the clinically demented and $7 \%$ of the non-demented, and was significantly associated with dementia (odds ratio/ OR 9.3, 95\%, confidence interval/CI 2.7-41.0) independent of other dementia-related neuropathologies.

\section{Honolulu-Asia Aging Study (HAAS)}

Pfeifer et al. [13] assessed CAA (controlling for other dementia-related neuropathologies) and clinical dementia in Japanese-American men in the HAAS. CAA was assessed in frontal, temporal, parietal and occipital cortices in 211 cases. Those with CAA were more likely to be older (86 versus 84 years of age) and carry at least one APOE $\varepsilon 4$ allele (23\% versus $6 \%$ ) than were those without CAA. The prevalence of CAA regardless of severity did not vary significantly between the demented and nondemented, with rates of 55\% and 38\% respectively (significance value not provided). Accordingly, the authors concluded that CAA regardless of severity did not confer a significant risk for dementia. There was however a significant difference in the prevalence of severe CAA, with the demented having a higher prevalence $(43 \%)$ than the non-demented (24\%).

Vantaa $85+$ study

Tanskanen et al. [35] assessed CAA in 74 (82\% women) Finnish individuals over the age of 95 who were part of the Vantaa 85+ study. CAA severity was assessed in frontal, parietal, temporal, cingulate and cerebellar cortices, and 
an average severity calculated. As reported by Pfeifer et al. [13], those with CAA were more likely to have at least one APOE $\varepsilon 4$ allele - $45 \%$ as compared to $8 \%$. Of the clinically demented, $59 \%$ had CAA as compared to $28 \%$ of the non-demented. It was reported that moderate or severe CAA conferred a risk for dementia (OR not reported).

From the summaries and Additional file 1 it is evident that in population-based samples, the prevalence of CAA is higher in the demented than the non-demented. On average, 55-59\% of those with clinical dementia had CAA (regardless of severity) compared to $28-38 \%$ of the nondemented. For severe CAA, prevalence appeared to decrease relatively equally across demented and nondemented groups, $37-43 \%$ of the clinically demented displaying severe CAA as compared to $7-24 \%$ of the nondemented. Only one study reported the prevalence of CAA to be non-significantly higher in demented than non-demented individuals however, this was for CAA regardless of severity. When only severe CAA was assessed, those with dementia had a higher prevalence than did the non-demented [13]. This suggests that in the population, severe CAA may be a better discriminator of clinical dementia than CAA regardless of severity.

\section{Summary of selected-sample studies}

Thirty-eight studies were identified for review and are summarised in Additional file 2. It can be seen in Additional file 2 that the prevalence of CAA, regardless of severity, is higher in the demented $(32-100 \%$ regardless of subtype or $47-100 \%$ for AD-only) than the nondemented $(0-77 \%)$ in selected samples. The studies that assessed severe CAA reported prevalence rates of $0-50 \%$ in the demented (6-50\% for AD-only) and $0-11 \%$ in the non-demented. Only five of the thirty-eight selected studies tested for an association between CAA and dementia $[34,37,40,44,45]$. All of those that did reported that cases with dementia had a significantly higher prevalence than those without, or that CAA prevalence correlated significantly with dementia. The only exception was the study by Jellinger and Attems [40] in which this was true for capillary CAA but not other forms of CAA.

\section{Discussion \\ How do CAA prevalences differ between population-based and selected-sample studies?}

There was greater variability in CAA prevalence rates in selected-sample studies than population-based studies. This may be due to differential bias between selected samples and the paucity of clinical information prior to death in most studies.

Estimates of CAA prevalence in the population studies were lower than in those from selected samples. This may be due to diagnostic differences (primarily neuropatho- logical methods in studies of selected samples as compared to clinical methods in population-based studies) and younger populations being assessed, perhaps including some cases of hereditary rather sporadic CAA. Only eight studies of selected samples employed a clinical diagnosis of dementia rather than a neuropathological confirmation of $\mathrm{AD}$ or $\mathrm{VaD}$. This is an important difference from population-based studies, all of which employed a clinical diagnosis, as neuropathological and clinical AD classification methods correspond imprecisely $[46,47]$.

The mean age of the cohorts in selected-sample studies was between 69-91, with participants in their 40s and 50s commonly included [e.g., [44,48-50]]. These studies on selected samples therefore included much younger cases than population-based studies. Given that populationbased studies most closely reflect the population at risk of disease, these findings highlight their important contribution to the understanding of pathological correlates of clinically determined dementia relevant to populations and patients. Evidence relating to the pathology of dementia needs to be obtained from both populationbased as well as from selected samples.

Both the population-based studies and those on selected samples employed various stains to assess CAA, including Congo red, thioflavin-S, anti-A $\beta$ immunohistochemistry and Weigert's haematoxylin. Some studies used multiple stains - either different stains for different cases [e.g., [51]] or anti-A $\beta$ immunostaining to validate Congo red-positive cases [e.g., [34]]. To the authors' knowledge, no study has directly compared the sensitivity and specificity of these staining methods in relation to the measurement of CAA. Haglund and Englund [49] assessed a small sample $(n=10)$ with both Congo red and anti-A $\beta$ immunohistochemistry. They reported that for 8 of the 10 cases, CAA severity appeared similar with both methods (A $\beta$ immunohistochemistry perhaps giving slightly higher severity grades), while the other 2 cases showed little Congo red positivity but strong labelling of vascular $A \beta$.

It is not only the staining method that may produce variability between studies, the pre-treatment methods and sampling strategies also contribute $[52,53]$. The selection of parenchymal and/or leptomeningeal samples is also important, as CAA severity is usually higher in the later [54]. The choice of cortical region(s) and the grading system employed in the scoring of CAA in terms of its scale (e.g., 0-3 or 0-4) and definition of severity, would have also contributed to inter-study variability.

\section{CAA at the population level including risk factors}

At the population level, it appears as though CAA prevalence rates are consistently higher in the demented than the non-demented, suggesting that CAA is an important 
dementia-related abnormality in a population context, particularly severe CAA. This finding is pertinent in light of recent reports of overlap in the prevalence rates between demented and non-demented cohorts of other dementia-related abnormalities such as plaques and tangles $[14,47]$.

Determination of the presence and severity of CAA may aid in neuropathological assessment that more closely resembles the clinical assessment of dementia. The MRCCFAS study reported the OR for risk of a clinical dementia diagnosis to be higher for severe CAA $(\mathrm{OR}=9.3,95 \% \mathrm{CI}$ 2.7-41.0) than either neocortical neuritic plaques $(\mathrm{OR}=$ $5.0,95 \%$ CI $1.2-29.8)$ or neocortical tangles $(\mathrm{OR}=4.6$, 95\%CI 1.5-15.8) [14]. Future work should elucidate whether the inclusion of CAA in the neuropathological assessments of dementias such as AD improves the specificity and sensitivity of classification relative to clinical dementia during life. Further, given that CAA is a potential discriminator of dementia from normal ageing, imaging methods that detect CAA in living individuals may aid in the differential diagnosis of clinical dementia syndromes $[5,12,55]$. CAA is a potential predictor of the development of dementia during life, for which treatment and management strategies might be developed. The presence of CAA in the living non-demented may also indicate a specific syndrome such as Vascular Cognitive Impairment No-Dementia (VCI-ND) [56] - this also needs to be investigated in the future.

Some studies [6,34,43,57-60] but not all [14,48,61] have found that increasing age in the elderly is a risk factor for CAA. In a community sample of 100 individuals 50-91 years, Mastaglia et al. [62] found CAA prevalence to increase with age to a maximum in those over 90 . As yet there is no evidence that the prevalence of CAA varies with sex $[7,43]$. Cerebrovascular disease (e.g., atherosclerosis) is another possible risk factor for CAA. It has been suggested to affect the efficiency of $A \beta$ removal by perivascular drainage, leading to CAA [63]. However, hypertension, diabetes mellitus and hyperlipidemia do not appear to be risk factors for CAA [60].

The $\varepsilon 4$ allele of the APOE gene has been reported to be a risk factor for CAA as it is for $\mathrm{AD}$ [64-68] and this was seen in two of the population-based studies reviewed here $[13,35]$. It has been suggested that the association between the APOE $\varepsilon 4$ allele and CAA is due to the $\varepsilon 4$ allele being related to vascular rather than parenchymal accumulation of $A \beta$ [64]. The APOE $\varepsilon 4 / \varepsilon 4$ genotype has been associated with CAA-related inflammation [69], while the $\varepsilon 2$ allele has been reported to be a risk factor for CAArelated haemorrhage in both those with and those without $\mathrm{AD}[65,70]$.

\section{How clinical studies can inform these findings}

Studies of clinic and/or necropsy cohorts are valuable for determining the implications of CAA at a population level. For instance, these studies have found that many neurological events induced by CAA can themselves compromise neurological integrity and cognitive function. For example, CAA increases vessel wall fragility and increases the risk of cortical and subcortical intracerebral haemorrhage $[5,71]$, carrying a high risk of poor neurological and cognitive outcome [72]. CAA may impair blood flow, leading to ischemic damage to the cerebral cortex and white matter, which is also associated with neurological and cognitive impairment [73-75]. CAA is associated with failure of drainage of interstitial fluid from cerebral white matter in $\mathrm{AD}$ and the pathogenesis of leukoaraiosis [76]. Further, the $A \beta$ peptide that accumulates in CAA can provoke inflammation/vasculitis in a small subset of individuals $[69,77]$ with both microglia and T-cells involved [78]. CAA-related inflammation has also been proposed to be related to severe cognitive decline due to circulatory dysfunction $[69,78]$. Thus, patients who develop haemorrhage, ischaemia, white matter damage or inflammation as complications of CAA are at risk of further cognitive impairment.

The type of vessel involved and distribution of CAA may differentially affect cognition. It was reported that capillary CAA is more closely associated with impaired cognition than is CAA of larger blood vessels [30,79]. Further, although CAA is most prevalent in the posterior regions of the cerebral hemispheres, the association between CAA and clinical dementia has been reported to be strongest for frontal CAA [37].

\section{Possible limitations and future directions}

The four population-based studies reviewed here employed relatively crude measures of CAA. There were varying attempts to take into account the interactions with a wide range of other dementia-related pathologies and the severity of CAA. No study took into account the distribution of CAA, the presence of inflammation and the type of vessel affected. All these factors have been reported to influence the association with cognition [e.g., $[30,37,79,80]]$.

Population-based studies, as with studies on selected samples, face some important stumbling blocks in the investigation of CAA. The distribution of CAA is variable [4] and its detection critically dependent of the extent and distribution of histological sampling. There is likely to be an under-diagnosis of CAA even in severe cases [18]. There is currently no consensus as to how to sample for or detect CAA or grade its severity. Full evaluation of CAA is most satisfactorily assessed by isolating cerebral and leptome- 
ningeal vessels from the brain and staining for amyloid with Thioflavin $[22,76]$. A standard consensus method for detecting and classifying CAA would greatly facilitate future population-based multi-centre studies of CAA and such plans are underway.

\section{Conclusion}

CAA prevalence rates are higher in demented than nondemented old people in prospective population-based studies. This suggests that CAA is a more significant dementia-related abnormality than previously recognised and underscores the need to understand the aetiology and pathogenesis of CAA and its contribution to dementia in the population.

\section{Competing interests}

The authors declare that they have no competing interests.

\section{Authors' contributions}

All authors drafted and edited the manuscript, HADK also carried out the systematic review.

\section{Additional material}

\section{Additional file 1}

Additional table 1. Prevalence (to nearest whole number) of CAA in population-based studies regardless of severity and relative to severe CAA only in the demented and non-demented, as well as the significance of association between CAA and clinical dementia.

Click here for file

[http://www.biomedcentral.com/content/supplementary/14712377-9-3-S1.doc]

\section{Additional file 2}

Additional table 2. Prevalence (to nearest whole number) of CAA in studies using selected non-population based samples in the demented and non-demented, as well as the significance of association between CAA and clinical dementia (if given) ordered by date of publication.

Click here for file

[http://www.biomedcentral.com/content/supplementary/1471-

2377-9-3-S2.doc]

\section{Acknowledgements}

HADK is supported by a BUPA Foundation grant (RHAG/094).

\section{References}

I. Lowe J, Mirra S, Hyman B, Dickson D: Ageing and Dementia. In Greenfield's Neuropathology 8th edition. Edited by: Love S, Ellison D. London: Hodder Arnold; 2008: 1031-I I 52.

2. Revesz T, Ghiso J, Lashley T, Plant G, Rostagno A, Frangione B, Holton JL: Cerebral amyloid angiopathies: a pathologic, biochemical, and genetic view. I Neuropathol Exp Neurol 2003, 62(9):885-898.

3. Zekry D, Duyckaerts C, Belmin J, Geoffre C, Moulias R, Hauw JJ: Cerebral amyloid angiopathy in the elderly: vessel walls changes and relationship with dementia. Acta Neuropathol 2003, 106(4):367-373.

4. Vinters HV: Cerebral amyloid angiopathy. A critical review. Stroke 1987, 18(2):311-324.
5. Salat DH, Smith EE, Tuch DS, Benner T, Pappu V, Schwab KM, Gurol ME, Rosas HD, Rosand J, Greenberg SM: White matter alterations in cerebral amyloid angiopathy measured by diffusion tensor imaging. Stroke 2006, 37(7): |759-1764.

6. Vinters HV, Gilbert J]: Cerebral amyloid angiopathy: incidence and complications in the aging brain. II. The distribution of amyloid vascular changes. Stroke 1983, 14(6):924-928.

7. Xu D, Yang $C$, Wang $L$ : Cerebral amyloid angiopathy in aged Chinese: a clinico-neuropathological study. Acta Neuropathol 2003, I06(I):89-9I.

8. Scholz W: Studien zur Pathologie der Hirngefässe II. Die drusige Entartung der Hirnarterien und -capillaren. (Eine Form seniler Gefässerkrankung). Zeitshrift für die gesamte Neurologie und Psychiatrie 1938, 162:694-715.

9. Coria $F$, Castano EM, Frangione B: Brain amyloid in normal aging and cerebral amyloid angiopathy is antigenically related to Alzheimer's disease beta-protein. Am J Pathol 1987, I 29(3):422-428.

10. Glenner GG: Amyloid deposits and amyloidosis: the betafibrilloses (second of two parts). N Engl J Med 1980, 302(24): 1333-1343.

II. Glenner GG: Amyloid deposits and amyloidosis. The betafibrilloses (first of two parts). N Engl J Med 1980, 302(23): $1283-1292$.

12. Greenberg SM, Gurol ME, Rosand J, Smith EE: Amyloid angiopathy-related vascular cognitive impairment. Stroke 2004, 35(I I Suppl I):2616-2619.

13. Pfeifer LA, White LR, Ross GW, Petrovitch H, Launer LJ: Cerebral amyloid angiopathy and cognitive function: the HAAS autopsy study. Neurology 2002, 58(I I): 1629-1634.

14. MRC-CFAS: Pathological correlates of late-onset dementia in a multicentre, community-based population in England and Wales. Neuropathology Group of the Medical Research Council Cognitive Function and Ageing Study (MRC CFAS). Lancet 200I, 357(925 I): 169-175.

15. Greenberg SM: Cerebral amyloid angiopathy and dementia: Two amyloids are worse than one. 2002:1587-1588.

16. Weller RO, Nicoll JA: Cerebral amyloid angiopathy: pathogenesis and effects on the ageing and Alzheimer brain. Neurol Res 2003, 25(6):6II I-6I6.

17. Haan J, Roos RA: Comparison between the Icelandic and Dutch forms of hereditary cerebral amyloid angiopathy. Clin Neurol Neurosurg 1992, 94(Suppl):S82-83.

18. Attems J: Sporadic cerebral amyloid angiopathy: pathology, clinical implications, and possible pathomechanisms. Acta Neuropathol 2005, I I0(4):345-359.

19. Herzig MC, van Nostrand WE, Jucker M: Mechanism of cerebral beta-amyloid angiopathy: murine and cellular models. Brain Pathol 2006, 16(1):40-54.

20. Weller RO, Subash M, Preston SD, Mazanti I, Carare RO: Perivascular drainage of amyloid-beta peptides from the brain and its failure in cerebral amyloid angiopathy and Alzheimer's disease. Brain Pathol 2008, I 8(2):253-266.

21. Carare RO, Bernardes-Silva M, Newman TA, Page AM, Nicoll JA, Perry VH, Weller RO: Solutes, but not cells, drain from the brain parenchyma along basement membranes of capillaries and arteries: significance for cerebral amyloid angiopathy and neuroimmunology. Neuropathol Appl Neurobiol 2008, 34(2): $|3|-\mid 44$.

22. Weller RO, Massey A, Newman TA, Hutchings M, Kuo YM, Roher AE: Cerebral amyloid angiopathy: amyloid beta accumulates in putative interstitial fluid drainage pathways in Alzheimer's disease. Am J Pathol 1998, I53(3):725-733.

23. Preston SD, Steart PV, Wilkinson A, Nicoll JA, Weller RO: Capillary and arterial cerebral amyloid angiopathy in Alzheimer's disease: defining the perivascular route for the elimination of amyloid beta from the human brain. Neuropathol Appl Neurobiol 2003, 29(2): 106-117.

24. Weller RO, Cohen NR, Nicoll JA: Cerebrovascular disease and the pathophysiology of Alzheimer's disease. Implications for therapy. Panminerva Med 2004, 46(4):239-25I.

25. Schley D, Carare-Nnadi R, Please CP, Perry VH, Weller RO: Mechanisms to explain the reverse perivascular transport of solutes out of the brain. J Theor Biol 2006, 238(4):962-974.

26. McCarron MO, Nicoll JA, Stewart J, Ironside JW, Mann DM, Love S, Graham DI, Dewar D: The apolipoprotein E epsilon2 allele and 
the pathological features in cerebral amyloid angiopathyrelated hemorrhage. I Neuropathol Exp Neurol 1999, 58(7):7| I-7I8.

27. Zhang-Nunes SX, Maat-Schieman ML, van Duinen SG, Roos RA, Frosch MP, Greenberg SM: The cerebral beta-amyloid angiopathies: hereditary and sporadic. Brain Pathol 2006, I 6( I):30-39.

28. Lue LF, Kuo YM, Roher AE, Brachova L, Shen Y, Sue L, Beach T, Kurth $J H$, Rydel RE, Rogers J: Soluble amyloid beta peptide concentration as a predictor of synaptic change in Alzheimer's disease. Am J Pathol 1999, I 55(3):853-862.

29. McLean CA, Cherny RA, Fraser FW, Fuller SJ, Smith MJ, Beyreuther $\mathrm{K}$, Bush Al, Masters $\mathrm{CL}$ : Soluble pool of Abeta amyloid as a determinant of severity of neurodegeneration in Alzheimer's disease. Ann Neurol 1999, 46(6):860-866.

30. Attems J, Jellinger KA: Only cerebral capillary amyloid angiopathy correlates with Alzheimer pathology - a pilot study. Acta Neuropathol 2004, I07(2):83-90.

31. Mandybur TI: The incidence of cerebral amyloid angiopathy in Alzheimer's disease. Neurology 1975, 25(2): I20-126.

32. Gandy S: The role of cerebral amyloid beta accumulation in common forms of Alzheimer disease. I Clin Invest 2005, I I 5(5): I I2I-I I29.

33. Williams S, Chalmers K, Wilcock GK, Love S: Relationship of neurofibrillary pathology to cerebral amyloid angiopathy in Alzheimer's disease. Neuropathol Appl Neurobiol 2005 3 I (4):4|4-42I.

34. Yamada M: Risk factors for cerebral amyloid angiopathy in the elderly. Ann N Y Acad Sci 2002, 977:37-44.

35. Tanskanen M, Lindsberg PJ, Tienari PJ, Polvikoski T, Sulkava R, Verkkoniemi A, Rastas S, Paetau A, Kiuru-Enari S: Cerebral amyloid angiopathy in a 95+ cohort: complement activation and apolipoprotein E (ApoE) genotype. Neuropathol Appl Neurobiol 2005, 3 I(6):589-599.

36. Tian J, Shi J, Mann DM: Cerebral amyloid angiopathy and dementia. Panminerva Med 2004, 46(4):253-264

37. Attems J, Quass M, Jellinger KA, Lintner F: Topographical distribution of cerebral amyloid angiopathy and its effect on cognitive decline are influenced by Alzheimer disease pathology. J Neurol Sci 2007, 257(I-2):49-55.

38. Schoenmaker N, van Gool WA: The age gap between patients in clinical studies and in the general population: a pitfall for dementia research. Lancet Neurol 2004, 3( I 0):627-630.

39. Zaccai J, Ince P, Brayne C: Population-based neuropathological studies of dementia: design, methods and areas of investigation - a systematic review. BMC Neurol 2006, 6:2.

40. Jellinger KA, Attems J: Prevalence and impact of cerebrovascular pathology in Alzheimer's disease and parkinsonism. Acto Neurol Scand 2006, I I 4( I):38-46.

4I. Jellinger KA, Attems J: Prevalence and pathogenic role of cerebrovascular lesions in Alzheimer disease. J Neurol Sci 2005, 229-230:37-41.

42. Xuereb JH, Brayne C, Dufouil C, Gertz H, Wischik C, Harrington C, Mukaetova-Ladinska E, McGee MA, O'Sullivan A, O'Connor D, et al: Neuropathological findings in the very old. Results from the first IOI brains of a population-based longitudinal study of dementing disorders. Ann N Y Acad Sci 2000, 903:490-496.

43. Masuda J, Tanaka K, Ueda K, Omae T: Autopsy study of incidence and distribution of cerebral amyloid angiopathy in Hisayama, Japan. Stroke 1988, I9(2):205-210.

44. Bergeron C, Ranalli PJ, Miceli PN: Amyloid angiopathy in Alzheimer's disease. Can J Neurol Sci 1987, I 4(4):564-569.

45. Sonnen JA, Larson EB, Crane PK, Haneuse S, Li G, Schellenberg GD, Craft S, Leverenz JB, Montine TJ: Pathological correlates of dementia in a longitudinal, population-based sample of aging. Ann Neurol 2007, 62(4):406-4I3.

46. Gearing M, Mirra SS, Hedreen JC, Sumi SM, Hansen LA, Heyman A The Consortium to Establish a Registry for Alzheimer's Disease (CERAD). Part X. Neuropathology Confirmation of the Clinical Diagnosis of Alzheimer's Disease. Neurology 1995 , 45(3):46I-466.

47. Polvikoski T, Sulkava R, Myllykangas L, Notkola IL, Niinisto L, Verkkoniemi A, Kainulainen K, Kontula K, Perez-Tur J, Hardy J, et al. Prevalence of Alzheimer's disease in very elderly people: a prospective neuropathological study. Neurology 2001, 56(12): 1690-1696.
48. Esiri MM, Wilcock GK: Cerebral amyloid angiopathy in dementia and old age. 1986: $\mid 221-1226$

49. Haglund M, Englund E: Cerebral amyloid angiopathy, white matter lesions and Alzheimer encephalopathy - a histopathological assessment. Dement Geriatr Cogn Disord 2002, |4(3): | $61-166$.

50. Vogelgesang S, Warzok RW, Cascorbi I, Kunert-Keil C, Schroeder E, Kroemer HK, Siegmund W, Walker LC, Pahnke J: The role of $\mathbf{P}$. glycoprotein in cerebral amyloid angiopathy; implications for the early pathogenesis of Alzheimer's disease. Curr Alzheimer Res 2004, I(2): | 2 |- I 25.

5I. Ellis RJ, Olichney JM, Thal LJ, Mirra SS, Morris JC, Beekly D, Heyman $A$ : Cerebral amyloid angiopathy in the brains of patients with Alzheimer's disease: the CERAD experience, Part XV. Neurology 1996, 46(6): I592-I596.

52. Alafuzoff I, Pikkarainen M, Arzberger T, Thal DR, Al-Sarraj S, Bell J, Bodi I, Budka H, Capetillo-Zarate E, Ferrer I, et al.: Inter-laboratory comparison of neuropathological assessments of beta-amyloid protein: a study of the BrainNet Europe consortium. Acta Neuropathol 2008, I I 5(5):533-546.

53. Bely M, Makovitzky J: Sensitivity and specificity of Congo red staining according to Romhanyi. Comparison with Puchtler's or Bennhold's methods. Acta Histochem 2006, I 08(3): |75- I80.

54. Greenberg SM, Vonsattel J-PG: Diagnosis of Cerebral Amyloid Angiopathy: Sensitivity and Specificity of Cortical Biopsy. Stroke 1997, 28(7): |4|8-|422.

55. Knudsen KA, Rosand J, Karluk D, Greenberg SM: Clinical diagnosis of cerebral amyloid angiopathy: Validation of the Boston Criteria. Neurology 200I, 56(4):537-539.

56. Moorhouse P, Rockwood K: Vascular cognitive impairment: current concepts and clinical developments. The Lancet Neurology 2008, 7(3):246-255

57. Hart MN, Merz P, Bennett-Gray J, Menezes AH, Goeken JA, Schelper RL, Wisniewski HM: beta-amyloid protein of Alzheimer's disease is found in cerebral and spinal cord vascular malformations. Am J Pathol I 988, I32(I): I67-I72.

58. Love S, Nicoll JAR, Hughes A, Wilcock GK: APOE and cerebra amyloid angiopathy in the elderly. NeuroReport 2003, I4( I I): I535-I536.

59. Tomonaga $M$ : Cerebral amyloid angiopathy in the elderly. JAm Geriatr Soc 1981, 29(4): I5 I-157.

60. Yamada M, Tsukagoshi H, Otomo E, Hayakawa M: Cerebral amyloid angiopathy in the aged. J Neurol I 987, 234(6):37I-376

61. Mountjoy CQ, Tomlinson BE, Gibson PH: Amyloid and senile plaques and cerebral blood vessels. A semi-quantitative investigation of a possible relationship. J Neurol Sci 1982 , 57(I):89-103

62. Mastaglia FL, Byrnes ML, Johnsen RD, Kakulas BA: Prevalence of cerebral vascular amyloid-beta deposition and stroke in an aging Australian population: a postmortem study. J Clin Neurosci 2003, I0(2): 186-189.

63. Weller RO, Yow HY, Preston SD, Mazanti I, Nicoll JA: Cerebrovascular disease is a major factor in the failure of elimination of Abeta from the aging human brain: implications for therapy of Alzheimer's disease. Ann N Y Acad Sci 2002, 977: I62-I 68.

64. Chalmers K, Wilcock GK, Love S: APOE epsilon 4 influences the pathological phenotype of Alzheimer's disease by favouring cerebrovascular over parenchymal accumulation of $A$ beta protein. Neuropathol Appl Neurobiol 2003, 29(3):23 I-238.

65. Greenberg SM, Rebeck GW, Vonsattel JP, Gomez-Isla T, Hyman BT: Apolipoprotein $E$ epsilon 4 and cerebral hemorrhage associated with amyloid angiopathy. Ann Neurol 1995, 38(2):254-259.

66. McCarron MO, Nicoll JA: Apolipoprotein E genotype and cerebral amyloid angiopathy-related hemorrhage. Ann N Y Acad Sci 2000, 903:176-179.

67. Premkumar DR, Cohen DL, Hedera P, Friedland RP, Kalaria RN: Apolipoprotein E-epsilon4 alleles in cerebral amyloid angiopathy and cerebrovascular pathology associated with Alzheimer's disease. Am J Pathol 1996, I 48(6):2083-2095.

68. Trembath D, Ervin JF, Broom L, Szymanski M, Welsh-Bohmer K, Pieper C, Hulette CM: The distribution of cerebrovascular amyloid in Alzheimer's disease varies with ApoE genotype. Acta Neuropathol 2007, I I 3( I):23-3I.

69. Eng JA, Frosch MP, Choi K, Rebeck GW, Greenberg SM: Clinical manifestations of cerebral amyloid angiopathy-related inflammation. Ann Neurol 2004, 55(2):250-256. 
70. Nicoll JA, Burnett C, Love S, Graham DI, Ironside JW, Vinters HV: High frequency of apolipoprotein $E$ epsilon 2 in patients with cerebral hemorrhage due to cerebral amyloid angiopathy. Ann Neurol 1996, 39(5):682-683.

7I. Tian J, Shi J, Bailey K, Mann DM: Relationships between arteriosclerosis, cerebral amyloid angiopathy and myelin loss from cerebral cortical white matter in Alzheimer's disease. Neuropathol Appl Neurobiol 2004, 30(I):46-56.

72. Tatemichi TK, Desmond DW, Mayeux R, Paik M, Stern Y, Sano M, Remien RH, Williams JBW, Mohr JP, Hauser WA, et al.: Dementia after stroke: Baseline frequency, risks, and clinical features in a hospitalized cohort. Neurology 1992, 42(6): I 185.

73. Fernando MS, Ince PG: Vascular pathologies and cognition in a population-based cohort of elderly people. J Neurol Sci 2004, 226(I-2): 13-17.

74. Jellinger KA: The pathology of ischemic-vascular dementia: an update. J Neurol Sci 2002, 203-204: I53-I57.

75. Pantoni L, Garcia JH: Cognitive impairment and cellular/vascular changes in the cerebral white matter. Ann N Y Acad Sci 1997, 826:92-102.

76. Roher AE, Kuo YM, Esh C, Knebel C, Weiss N, Kalback W, Luehrs DC, Childress JL, Beach TG, Weller RO, et al.: Cortical and leptomeningeal cerebrovascular amyloid and white matter pathology in Alzheimer's disease. Mol Med 2003, 9(34): $112-122$.

77. Scolding NJ, Joseph F, Kirby PA, Mazanti I, Gray F, Mikol J, Ellison D, Hilton DA, Williams TL, MacKenzie JM, et al.: Abeta-related angiitis: primary angiitis of the central nervous system associated with cerebral amyloid angiopathy. Brain 2005, I 28(Pt 3):500-5I5.

78. Greenberg SM, Bacskai BJ, Hyman BT: Alzheimer disease's double-edged vaccine. Nat Med 2003, 9(4):389-390.

79. Jellinger KA: Alzheimer disease and cerebrovascular pathology: an update. J Neural Transm 2002, 109(5-6):8|3-836.

80. Thal DR, Ghebremedhin E, Orantes M, Wiestler OD: Vascular pathology in Alzheimer disease: correlation of cerebral amyloid angiopathy and arteriosclerosis/lipohyalinosis with cognitive decline. J Neuropathol Exp Neurol 2003, 62(12): I 287-I30I.

8I. Jellinger K: Cerebrovascular amyloidosis with cerebral hemorrhage. J Neurol 1977, 2 I 4(3): 195-206.

82. Glenner GG, Henry JH, Fujihara S: Congophilic angiopathy in the pathogenesis of Alzheimer's degeneration. Ann Pathol 198I, I(2): $120-129$

83. Joachim CL, Morris JH, Selkoe DJ: Clinically diagnosed Alzheimer's disease: autopsy results in 150 cases. Ann Neurol 1988, 24(I):50-56.

84. Dickson DW, Crystal HA, Mattiace LA, Masur DM, Blau AD, Davies $\mathrm{P}$, Yen SH, Aronson MK: Identification of normal and pathological aging in prospectively studied nondemented elderly humans. Neurobiol Aging 1992, I3(1): I79-189.

85. Lopez OL, Claassen D: Cerebral amyloid angiopathy in Alzheimer's disease: Clinicopathological correlations. Dement Geriatr Cogn Disord 1991:285-290.

86. Wu E, Lipton RB, Dickson DW: Amyloid angiopathy in diffuse Lewy body disease. Neurology 1992, 42(I I):2।31-2।35

87. Ogeng'o JA, Cohen DL, Sayi JG, Matuja WB, Chande HM, Kitinya JN Kimani JK, Friedland RP, Mori H, Kalaria RN: Cerebral amyloid beta protein deposits and other Alzheimer lesions in nondemented elderly east Africans. Brain Pathol 1996, 6(2): I0 I- 107.

88. Olichney JM, Hansen LA, Galasko D, Saitoh T, Hofstetter CR, Katzman $R$, Thal Ll: The apolipoprotein $E$ epsilon 4 allele is associated with increased neuritic plaques and cerebral amyloid angiopathy in Alzheimer's disease and Lewy body variant. Neurology 1996, 47(I): 190-196.

89. Davis DG, Schmitt FA, Wekstein DR, Markesbery WR: Alzheimer neuropathologic alterations in aged cognitively normal subjects. I Neuropathol Exp Neurol 1999, 58(4):376-388.

90. Zarow C, Zaias B, Lyness SA, Chui H: Cerebral amyloid angiopathy in Alzheimer disease is associated with apolipoprotein E4 and cortical neuron loss. Alzheimer Dis Assoc Disord 1999, I3(I): I-8.

91. Del Ser T, Hachinski V, Merskey H, Munoz DG: Clinical and pathologic features of two groups of patients with dementia with Lewy bodies: effect of coexisting Alzheimer-type lesion load. Alzheimer Dis Assoc Disord 200 I, I 5(I):31-44.
92. Jellinger KA, Attems ]: Incidence of cerebrovascular lesions in Alzheimer's disease: a postmortem study. Acta Neuropathol 2003, I05(I): 14-17.

93. Jellinger KA, Mitter-Ferstl E: The impact of cerebrovascular lesions in Alzheimer disease - a comparative autopsy study. J Neurol 2003, 250(9): 1050- 055.

94. Tian J, Shi J, Bailey K, Mann DMA: Negative association between amyloid plaques and cerebral amyloid angiopathy in Alzheimer's disease. Neuroscience Letters 2003, 352(2): |37-|40.

95. Haglund M, Sjobeck M, England E: Severe Cerebral Amyloid Angiopathy Characterizes an Underestimated Variant of Vascular Dementia. Dement Geriatr Cogn Disord 2004, I 8(2): | 32-। 37.

96. Tian J, Shi J, Bailey K, Lendon C, Pickering-Brown S, Mann D: Association between apolipoprotein $\mathrm{E}$ e4 allele and arteriosclerosis, cerebral amyloid angiopathy, and cerebral white matter damage in Alzheimer's disease. Journal of Neurology, Neurosurgery \& Psychiatry 2004, 75(5):696-699.

97. Haglund M, Passant U, Sjobeck M, Ghebremedhin E, Englund E: Cerebral amyloid angiopathy and cortical microinfarcts as putative substrates of vascular dementia. Int J Geriatr Psychiatry 2006 2 I(7):68I-687

98. Tian J, Shi J, Smallman R, Iwatsubo T, Mann DM: Relationships in Alzheimer's disease between the extent of Abeta deposition in cerebral blood vessel walls, as cerebral amyloid angiopathy, and the amount of cerebrovascular smooth muscle cells and collagen. Neuropathol Appl Neurobiol 2006, 32(3):332-340.

99. Jellinger KA, Lauda F, Attems J: Sporadic cerebral amyloid angiopathy is not a frequent cause of spontaneous brain hemorrhage. European Journal of Neurology 2007, I 4(8):923-928.

100. Attems J, Lauda F, Jellinger KA: Unexpectedly low prevalence of intracerebral hemorrhages in sporadic cerebral amyloid angiopathy: an autopsy study. J Neurol 2008, 255(I):70-76.

10I. Jellinger KA, Attems J: Cerebral amyloid angiopathy in Lewy body disease. J Neural Transm 2008, I I 5(3):473-482.

102. Olichney JM, Hansen LA, Hofstetter CR, Grundman M, Katzman R, Thal L): Cerebral infarction in Alzheimer's disease is associated with severe amyloid angiopathy and hypertension. Arch Neurol 1995, 52(7):702-708.

103. Chalmers K, Wilcock G, Love S: Contributors to white matter damage in the frontal lobe in Alzheimer's disease. Neuropathol Appl Neurobiol 2005, 3 I(6):623-63I.

\section{Pre-publication history}

The pre-publication history for this paper can be accessed here:

http://www.biomedcentral.com/1471-2377/9/3/prepub

Publish with BioMed Central and every scientist can read your work free of charge

"BioMed Central will be the most significant development for disseminating the results of biomedical research in our lifetime. "

Sir Paul Nurse, Cancer Research UK

Your research papers will be:

- available free of charge to the entire biomedical community

- peer reviewed and published immediately upon acceptance

- cited in PubMed and archived on PubMed Centra

- yours - you keep the copyright 